\title{
POLYMERIZATION SHRINKAGE OF CURED DENTAL COMPOSITES WITH DIFFERENT RESIN MATRICES
}

\author{
Saad El-deen S Alghazawy*, Mohamed M Abdalla* and Khaled Noman**
}

\begin{abstract}
The purpose of this study was to evaluate the polymerization shrinkage of cured silorane based composite (Filtek ${ }^{\mathrm{TM}}$ P90) and methacrylate based composites (Filtek ${ }^{\mathrm{TM}}$ Z350XT) nanofilled and (Filtek ${ }^{\mathrm{TM}}$ Z250 XT) nanohybrid. A total of 45 specimens were prepared, they were divided into three main groups of 15 specimen for each according to the restorative material used (A); where "A1": Filtek p90, "A2": Filtek Z250XT and "A3": Filtek Z350XT. A rectangular glass slab was used for polymerization shrinkage measurements. The composite materials were condensed incrementally in the mold and covered with celluloid strip, then cured for 40 seconds by LED light curing. Four reference points were marked, then the distance between top and bottom of the uncured material (thickness of the specimen) was measured at each reference point,then the thickness of the specimen was repeatedly measured at the same reference points giving the measurements of the cured samples. The measurements were recorded using digital microscope. Results: It was found that there were statistically significant differences in maximum polymerization shrinkage between the same shade of the three resin formulations. Conclusion: Silorane based composites polymerized through ring opening polymerization is considered an excellent alternative to Bis GMA based composites regarding to their low shrinkage and polymerization stresses.
\end{abstract}

\section{INTRODUCTION}

For decades, dental amalgam has been the restorative material of choice. Although major health care organizations, have published policy statements confirming the safety of dental amalgam, there still is concern about the potential biohazards of mercury in amalgam and whether mercury can affect human health and the environment. These concerns have helped increase efforts to find or develop acceptable alternatives to amalgam ${ }^{(1)}$.

Resin based composites were advocated as a possible solution to this problem because they were mercury free and thermally nonconductive and they matched the shade of natural teeth and bonded to tooth structure readily with the use of adhesive systems ${ }^{(2)}$.

Esthetics has gained more importance day after day, which has made esthetic materials like composite resins the restorative materials of choice in many clinical situations ${ }^{(3)}$. In recent years, composite resin materials have been on the market with improved mechanical properties due to new filling concepts, changes in the matrix and improvement in curing conditions ${ }^{(4)}$.

It is well-documented that energy density of the light cure influences the degree of cure, depth of cure, and mechanical properties of a resin composite ${ }^{(5)}$. Polymerization shrinkage is an adverse side effect, which occurs to resin-based restorative materials. Clinical manifestations of polymerization shrinkage are exhibited as de-bonding at the adhesive interface, marginal discoloration, postoperative pain, recurrent caries and finally failure of the restoration ${ }^{(6)}$.

Volumetric shrinkage occurs when monomers in proximity react to establish a covalent bond. The distance between the two groups of atoms is reduced and there is a reduction in free volume, both of which

* Lecturer, Department of Dental Biomaterials, Al Azhar University.

** Professor, Department of Operative Dentistry, Al Azhar University. 
translate into volumetric shrinkage. The magnitude of volumetric shrinkage experienced by a composite is determined by its filler volume fraction and the composition and degree of conversion of the resin matrix ${ }^{(7) .}$

To reduce polymerization shrinkage, many attempts have been made to change the type of fillers or filler size and their surface silanization ${ }^{(8)}$. As well as improvements of conventional Bis-GMA based resins have been made to reduce the polymerization shrinkage of composite which are using different types of resin or minimize density(viscosity) such as UEDMA, Bis-EMA ${ }^{(9)}$.

The term "silorane" was introduced to represent hybrid monomer systems that contain both siloxane and oxirane structural moieties ${ }^{(10)}$.

The network of siloranes is generated by the cationic ring opening polymerization of the cycloaliphatic oxirane moieties, which stand for their low shrinkage and low polymerization stress. The cationic cure starts with the initiation process of an acidic cation which opens the oxirane ring and generates a new acidic center, carbonation. After the addition to an oxirane monomer, the epoxy ring is opened to form a chain, or in the case of two- or multifunctional monomers a network is formed ${ }^{(11)}$

Therefore, this study is designed to evaluate the effect of different resin matrices and fillers on reducing polymerization shrinkage of dental composite.

\section{MATERIALS AND METHODS}

A total of 45 specimens were prepared, they were divided into three main groups of 15 specimen for each according to the restorative material used (A) Silorane based composite (Filtek ${ }^{\mathrm{TM}}$ P90) (B) methacrylate-based composites (Filtek ${ }^{\mathrm{TM}} \mathrm{Z} 350 \mathrm{XT}$ ) nanofilled and (C) (Filtek ${ }^{\mathrm{TM}}$ Z250 XT) nanohybrid

\section{Determination of Polymerization Shrinkage:-}

\section{Mould Construction:}

A rectangular glass slab of dimensions $(50 \mathrm{x}$ $20 \times 2 \mathrm{~mm}$ ) was used for polymerization shrinkage measurements. Pieces of glass $2 \mathrm{~mm}$ in thickness were adhered on the glass slab to create square rooms on the slab of dimensions $(5 \times 5 \mathrm{~mm})$.

\section{Specimen Preparation:}

The composite materials were condensed incrementally in the mold and covered with celluloid strip, then cured for 40 seconds for each increment by LED light curing unit with, it's curing tip placed on direct contact with mold and perpendicular to it.

\section{Polymerization Shrinkage Test Procedure:}

Four reference points were marked. Five specimens were prepared for each resin composite material which was placed individually in the squared areas of the glass mould. A plastic spatula was used to remove the excess material and adapt the margins of the resin composite to the edges of the mould then a celluloid matrix covered the resin paste. The distance between top and bottom of the uncured material (thickness of the specimen) was measured at each reference point. These measurements were denoted as (L0). Finally, each previously prepared sample was cured for $40 \mathrm{sec}$. and then the thickness of the specimen was repeatedly measured at the same reference points giving the measurements of the cured samples (Lf)

It should be mentioned that the measurements were recorded using digital microscope integrated by image analysis software.

\section{Calculations of the polymerization shrinkage:}

Linear polymerization shrinkage $(\mathrm{Lin} \%)=\frac{\Delta \mathrm{L} X 100}{(\mathrm{Lc}+\mathrm{Lo})}$

Where:

$\Delta \mathrm{L}=\mathrm{L} 0-\mathrm{Lf}(\mu \mathrm{m})$ 
$\mathrm{L} 0=$ the thickness of the uncured specimen $(\mu \mathrm{m})$

$\mathrm{Lf}=$ the thickness of the specimen after curing $(\mu \mathrm{m})$

$\mathrm{Lc}=$ step height between the top of the glass mould surface and its bottom (corrective depth) $(\mu \mathrm{m})$

\section{RESULTS}

Data analysis was performed in several steps. Initially, descriptive statistics for each group results. Two-way analysis of variance ANOVA test of significance comparing variables affecting mean values. Statistical analysis was performed using Asistat 7.6 statistics software for Windows (Campina Grande, Paraiba state, Brazil). P values $\leq 0.05$ are considered to be statistically significant in all tests.

The mean values and standard deviation of polymerization shrinkage (\%) for all composite groups are summarized in table (1) and graphically drawn in figures (1).

Totally it was found that Nano-hybrid composite resin recorded statistically significant $(\mathrm{P}<0.05)$ highest polymerization shrinkage mean value $(2.482564 \pm 0.39 \%)$ followed by nano-filled composite resin $(1.977948 \pm 0.54 \%)$ while the lowest statistically non-significant mean value recorded by silorane composite $(1.828291 \pm 0.17 \%$

TABLE (1) Comparison between total polymerization shrinkage results (Mean values \pm SDs) as function of composite

\begin{tabular}{|c|c|c|c|c|c|}
\hline \multicolumn{2}{|r|}{ Variable } & Mean & $\pm \mathrm{SD}$ & Rank & Statistics \\
\hline \multirow{3}{*}{ 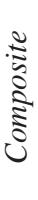 } & Silorane composite & 1.828291 & 0.17 & B & $P$ value \\
\hline & Nano-hybrid composite & 2.482564 & 0.39 & A & \multirow{2}{*}{$0.0082 *$} \\
\hline & Nano-filled composite & 1.977948 & 0.54 & B & \\
\hline
\end{tabular}

Different letter in the same column indicating statistically significant difference $(p<0.05)$. *; significant $(p<0.05) n s ;$ non-significant $(p>0.05)$

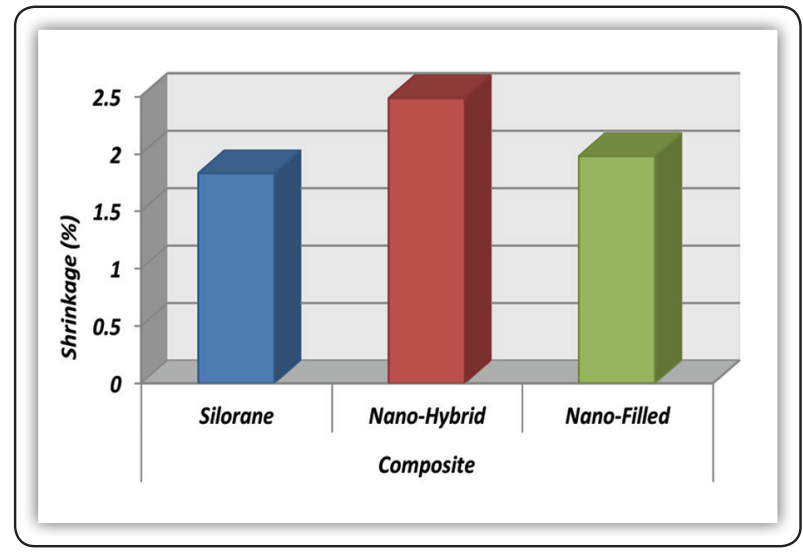

FIG (1) A column chart of total polymerization shrinkage mean values as function of composite

\section{DISCUSSION}

Nano hybrid composite, nano filled composite and silorane are some of the marketed composite restorative materials. This study investigated the effect of these different resin matrices and fillers on reducing polymerization shrinkage of dental composite.

Despite the remarkable developments in the technology of the composite resin restorative materials, clinical failures of composite restorations are still reported, particularly when composites are placed in stress bearing areas ${ }^{(12)}$.

At all specimen thicknesses, statistically significant differences in maximum polymerization shrinkage were observed between the same shades of the three resin products.

Polymerization shrinkage is an inevitable outcome of the polymerization process. The Van der Waals forces that hold the molecules together convert to covalent bonds, and such conversion is simultaneously accompanied by reductions in molecular distance and free volume. These reductions bring about polymerization shrinkage, which then produces a stress in resin composites during curing. Several causative factors for polymerization shrinkage have been identified, 
amongst which are several material formulation factors such as filler content, monomer chemistry, monomer structure, and additives ${ }^{(13)}$.

Similarly, material polymerization factors that have been identified to affect polymerization shrinkage are namely the curing method, placement technique, and catalyst and inhibitor concentration Amongst these factors, the filler content (in other words, the monomer content) is directly correlated with polymerization shrinkage and contraction stress in dental composite materials ${ }^{(14)}$.

Apart from filler content, monomer formulation and monomer content also affect polymerization shrinkage. It has been reported that shrinkage values for Bis-GMA (5.2\%) and TEGDMA (12.5\%) are substantially higher than those displayed by typical composite resins ${ }^{(14)}$.

In most commercial composite resins, the base monomer used, Bis-GMA has very high viscosity. Such high viscosity can be lowered by adding lower molecular weight diluents, TEGDMA and UDMA, to render the composite resins more workable for the practitioners. However, the added diluent monomers increase the density of polymerizable carbon double bonds and may lead to more shrinkage ${ }^{(13)}$.

The results of the present study showed that polymerization shrinkage of silorane composite has the lowest value. This is in good agreement with measurements by Ernst and Meyer ${ }^{(14)}$, Showing the lowest stress development for siloranes among tested composite materials. The network of siloranes is generated by the cationic ring opening polymerization of the cycloaliphatic oxirane moieties, which stand for their low polymerization shrinkage .The cationic cure starts with the initiation process of an acidic action which opens the oxirane ring and generates a new acidic center. After the addition to an oxirane monomer, the epoxy ring is opened to form a chain, or in the case of two- or multifunctional monomers a network is formed ${ }^{(15)}$.
The most important difference is that methacrylates are cured by radical intermediates and oxiranes polymerize via cationic intermediates which explains the low polymerization shrinkage values of silorane in comparison to that of methacrylate composites ${ }^{(16)}$.

Also, from results of this study the nano ceramic composite has polymerization shrinkage values lower than that of nano hybrid composites which is in good agreement with results of Min-Huey Chen et $\mathrm{al}^{(17)}$.

Also, we agree with Condon and Ferracane whom found a significant correlation between filler content and polymerization shrinkage ${ }^{(18)}$.

The differences found on mean data for polymerization shrinkage of the tested materials are probably the result of different resin composition, modulus of elasticity, inorganic filler content or any other factor of each material. So according to our study composition of the organic matrix, type and number of inorganic particles controlled the amount of the polymerization shrinkage of the tested materials and played the most important role not the minimal role ${ }^{(19)}$.

\section{CONCLUSIONS}

Within the limitation of this study the following conclusions might be drawn

The analyzed Nano hybrid filled composite showed higher polymerization shrinkage value, when compared to silorane and nano filled composite materials.

Silorane based composites polymerized through ring opening polymerization is considered an excellent alternative to Bis GMA based composites regarding to their low shrinkage and polymerization stresses. 


\section{REFERENCES}

1. Finer Y, Santerre J. Influence of silanated filler content on the biodegradation of bisGMA/TEGDMA dental composite resins. Journal of Biomedical Materials Research Part A. 2007;81(1):75-84.

2. Fortin D, Vargas MA. The spectrum of composites: new techniques and materials. The Journal of the American Dental Association. 2000; 131:26-30.

3. García AH, Lozano MAM, Vila JC, Escribano AB, Galve PF. Composite resins. A review of the materials and clinical indications. Med Oral Patol Oral Cir Bucal. 2006;11(2):215-20.

4. Deliperi S, Bardwell DN. An alternative method to reduce polymerization shrinkage in direct posterior composite restorations. The Journal of the American Dental Association. 2002;133(10):1387-98.

5. Hse KM, Wei SH. Clinical evaluation of compomer in primary teeth: 1-year results. The Journal of the American Dental Association. 1997;128(8):1088-96.

6. Bayindir F, Ilday NO, Bayindir YZ, Karataş O, Gurpinar A. Color changes in resin cement polymerized with different curing lights under indirect restorations. Journal of Conservative Dentistry: 2016;19(1):46.

7. Voltarelli FR, Santos-Daroz CBd, Alves MC, Peris AR, March GM. Effect of different light-curing devices and aging procedures on composite knoop microhardness. Brazilian Oral Research. 2009; 23(4):473-79.

8. Vandewalle K, Roberts H, Tiba A, Charlton D. Thermal emission and curing efficiency of LED and halogen curing lights. Oper Dent. 2005; 30(2):257-64.

9. Price RB, Felix CA, Andreou P. Knoop hardness of ten resin composites irradiated with high-power LED and quartz-tungsten-halogen lights. Biomaterials. 2005;26(15):2631-41.

10. Briso AL, Fedel TM, Pereira SdM, Mauro SJ, Sundfeld
RH, Sundefeld ML. Influence of light curing source on microhardness of composite resins of different shades. Journal of Applied Oral Science. 2006;14(1):10-15.

11. Santos G, Medeiros I, Fellows C, Muench A, Braga R. Composite depth of cure obtained with QTH and LED units assessed by microhardness and micro-Raman spectroscopy. Operative Dentistry. 2007; 32(1):79-83.

12. Garoushi S, Vallittu PK, Watts DC, Lassila LV. Effect of nanofiller fractions and temperature on polymerization shrinkage on glass fiber reinforced filling material. Dental Materials. 2008; 24(5):606-10.

13. Stansbury J. Cyclopolymerizable monomers for use in dental resin composites. Journal of Dental Research. 1990;69(3):844-48

14. Ernst CP, Meyer GR, Klöcker K, Willershausen B. Determination of polymerization shrinkage stress by means of a photoelastic investigation. Dental Materials. 2004; 20(4):313-21

15. Yazici A, Ozgünaltay G, Dayangac B. The effect of different types of flowable restorative resins on microleakage of Class V cavities. Operative Dentistry. 2002; 28(6):773-8.

16. de Souza FB, Guimarães RP, Silva CHV. A clinical evaluation of packable and microhybrid resin composite restorations: one-year report. Quintessence international. 2005; 36(1).

17. Chen MH, Chen C-R, Hsu S-H, Sun S-P, Su W-F. Low shrinkage light curable nanocomposite for dental restorative material. Dental Materials. 2006; 22(2):138-45

18. Condon JR, Ferracane JL. Assessing the effect of composite formulation on polymerization stress. The Journal of the American Dental Association. 2000;131(4):497-503.

19. Labella R, Lambrechts P, Van Meerbeek B, Vanherle G. Polymerization shrinkage and elasticity of flowable composites and filled adhesives. Dental Materials. 1999; 15(2):128-37. 
